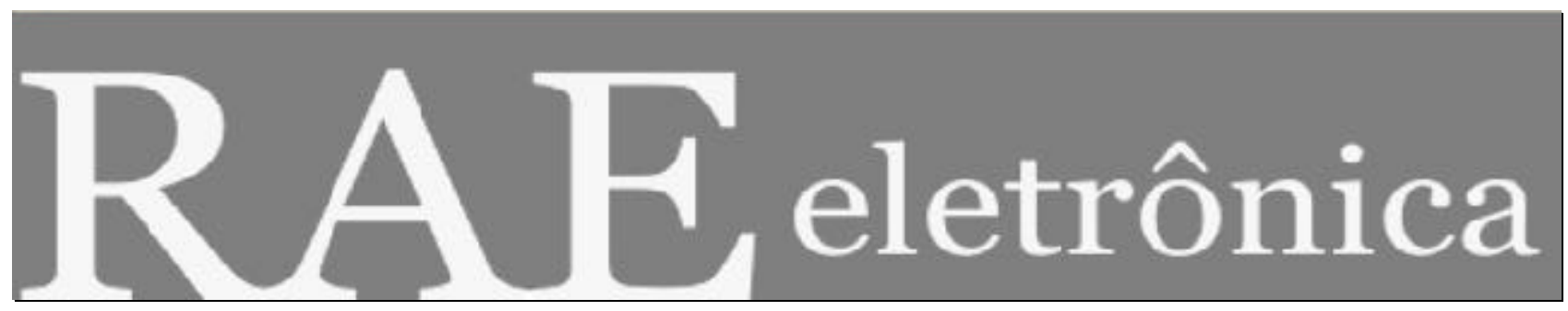

DIMENSÕES DE RISCOS PERCEBIDOS NAS COMPRAS PELA INTERNET

Por:

Michelle H. Kovacs

Salomão A. de Farias

RAE-eletrônica, v. 3, n. 2, Art. 15, jul./dez. 2004

http://www.rae.com.br/eletronica/index.cfm?FuseAction=Artigo\&ID=1 807\&Secao=MERCADO\&Vol ume $=3 \&$ Numero $=2 \&$ Ano $=2004$

CCopyright, 2004, RAE-eletrônica. Todos os direitos, inclusive de tradução, são reservados. É permitido citar parte de artigos sem autorização prévia desde que seja identificada a fonte. A reprodução total de artigos é proibida. Os artigos só devem ser usados para uso pessoal e nãocomercial. Em caso de dúvidas, consulte a redação: redacao@ rae.com.br.

A RAE-eletrônica é a revista on-line da FGV-EAESP, totalmente aberta e criada com o objetivo de agilizar a veiculação de trabalhos inéditos. Lançada em janeiro de 2002, com perfil acadêmico, é dedicada a professores, pesquisadores e estudantes. Para mais informações consulte o site www.rae.com.br/eletronica.

\title{
RAE-eletrônica
}

ISSN 1676-5648

(C2004 Fundação Getulio Vargas - Escola de Administração

de Empresas de São Paulo.

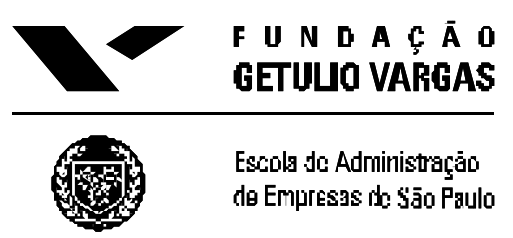




\section{DIMENSÕES DE RISCOS PERCEBIDOS NAS COMPRAS PELA INTERNET}

\section{RESUMO}

O objetivo desse artigo foi identificar dimensões de riscos percebidos na compra on-line por usuários da Internet que já compraram e pelos que nunca adquiriram produtos por este meio. O trabalho é resultado de um survey junto a uma amostra de 200 internautas. Destes, 111 participaram do grupo dos que nunca compraram pela rede e 89 dos que já compraram. O uso de estatísticas multivariadas destacou os riscos de proteção da informação, futura oportunidade perdida e dano físico das mercadorias adquiridas para os usuários que já compraram pela Internet e, para os que nunca compraram, acrescentamse a esses os riscos de perda da socialização e satisfação. Os usuários que nunca compraram pela rede perceberam mais dimensões de risco e em um maior grau do que os que já utilizaram a Internet como um meio de compras.

\section{ABSTRACT}

The purpuse of this article was to identify dimensions of perceived risks in the e-commerce by Internet users that have already bought products or services by this mode of buying and by those that haven't yet. The results of this investigation came by a survey using a sample of 200 Internet users. Of these, 111 were in the group that had never bough by the Internet, leaving 89 that already had. The use of multi-variable statistics identified the risks of information protection, future lost opportunity and physical damage of the acquired goods by the users that had already bought by the net and for the ones that had never bought, the risks of loss of socializing and satisfaction were added. The users that never bought by the e-commerce perceived more dimensions of risks and to a larger degree than those who had already used the Internet as mode of buying.

\section{PALAVRAS-CHAVE}

Internet, comércio eletrônico, comportamento do consumidor, risco percebido, tipologias de riscos.

\section{KEY WORDS}

Internet, electronic commerce, consumer behavior, perceived risks, kinds of risks. 


\section{A INTERNET COMO UM MEIO DE COMPRA}

$\mathrm{O}$ ambiente comercial da Internet possui características únicas que o distingue das formas tradicionais de comércio, trazendo um novo paradigma. A Internet é um ambiente de mídia interativo, não linear e que possui uma cultura peculiar. KIANI (1998) afirma que devido a estas diferenças, estão ocorrendo profundas variações na maneira como os usuários compram produtos e serviços.

Para LASCH (1998) um dos anseios identificados na compra pela Internet é por uma maior segurança, devido ao fato de que muitos consumidores ainda não estão conduzindo transações pela rede por conta dos riscos percebidos envolvidos na compra nesse meio. Os consumidores estão preocupados com a segurança do número do cartão de crédito e outras informações confidenciais transmitidas quando compram produtos e serviços na Internet. Existe também a preocupação sobre a legitimidade das empresas que vendem pela rede. De acordo com LASCH (1998), os consumidores estão corretamente preocupados com as questões de segurança no comércio pela Internet.

As empresas que pretenderem entrar no setor de comércio eletrônico devem comprovar aos seus consumidores em potencial, que seus sites são confiáveis, po is, de acordo com ENGEL et al. (1995), o risco percebido pode influenciar como os clientes irão responder às atividades de marketing.

O sucesso do comércio eletrônico depende da sua credibilidade, pois, nos mercados cada vez mais dinâmicos e competitivos, as empresas que têm maior probabilidade de sobreviver são, justamente, as que se preocupam com as expectativas, desejos e necessidades do cliente e que se equipam melhor que seus concorrentes para satisfazê-las (GIGLIO, 1996).

\section{O RISCO PERCEBIDO}

O risco percebido, segundo SOLOMON (1998), é a crença de que a compra de um produto ou serviço venha a ter consequiências negativas. $\mathrm{O}$ risco percebido pode também ser considerado como uma característica das decisões nas quais exista a incerteza sobre as conseqüências significantes que possam acontecer (SITKIN e PABLO, 1992).

ENGEL et al. (1995), por sua vez, consideram que o risco vai além da incerteza sobre as conseqüências, sendo uma expectativa pessoal de que uma perda possa ocorrer. De acordo com STEM et al. (1977), o risco percebido é uma função destas incertezas e das possíveis conseqüências. WEBER e BOTTOM (1989) comentam que estas decisões de risco são escolhas entre alternativas, nas quais pelo menos uma das possíveis conseqüências deve ser indesejada, ou menos desejada que as outras, para que o risco exista.

Apesar de observarem que o termo risco é tipicamente aplicado a resultados negativos, alguns pesquisadores, como SITKIN e PABLO (1992), afirmam que o risco inclui todo o espectro de resultados: tanto positivos quanto negativos. Isto se deve ao fato de que não é o resultado esperado em si que constitui o risco, mas o quanto este resultado pode ser considerado frustrante. Portanto, mesmo um resultado positivo pode ser decepcionante, caso seja considerado abaixo do nível a que se aspira. 


\section{Risco percebido nas compras pela Internet}

Em uma análise dos diversos tipos de riscos percebidos encontrados na literatura supõe-se que as compras pela Internet podem desencadear alguns novos tipos de risco, como por exe mplo, o risco da privacidade e segurança das informações transmitidas (MIYAZAKI e FERNANDEZ, 2000; WEBER e ROEHL, 1999; GONÇALVES et al., 1998; LASCH, 1998; ROHM e MILNE, 1998).

Em uma pesquisa realizada por ROHM e MILNE (1998), os resultados indicaram que grande parte dos usuários da Internet, tanto os que efetuam compras por esse meio bem como os que nunca compraram, têm uma série de preocupações quanto à privacidade das informações, incluindo a aquisição e sua disseminação pelas empresas.

De acordo com LASCH (1998), os consumidores possivelmente recebem grande influência das constantes notícias na mídia de massa sobre fraudes cometidas por hackers, potencializando ainda mais tal receio. Em um estudo realizado por WEBER e ROEHL (1999), os resultados indicaram que a segurança é um ponto chave, visto que $77,8 \%$ dos usuários que não compram pela rede afirmam que fornecer o número do cartão de crédito é o maior motivo de não efetuarem compras on-line.

No Brasil, segundo pesquisa realizada por GONÇALVES et al. (1998), verificourse que 66,67\% dos internautas não confiam nas compras realizadas na Internet. As principais razões para essa falta de confiança foram: possibilidade do número de cartão de crédito ser utilizado por outros, pagamento adiantado sem garantia de recebimento da mercadoria e falta de informação em geral. Na mesma pesquisa foi indagado ao respondente se compraria na Internet caso esta oferecesse total segurança nas informações transmitidas, e verificoutse que 91,4\% realizariam compras. A segurança na transmissão dos dados então surge como o grande desafio para um crescimento efetivo das transações comerciais na rede (GONÇALVES et al., 1998).

Ao enviar dados pessoais pela Internet o consumidor fica exposto, também, ao comércio desses dados pelas próprias empresas, desencadeando, assim, o receio do fim da privacidade, como citado por ABENE (apud NUNOMURA, 1998), podendo surgir o risco social, em que a privacidade seja invadida sem o devido conhecimento e consentimento prévio. Cerca de $57,7 \%$ da amostra do estudo realizado por WEBER e ROEHL (1999) não compra pela Internet por questões de privacidade. Segundo MIYAZAKI e FERNANDEZ (2000), a maior consequiência ética na coleta e gerenciamento de dados dos consumidores é a privacidade destas informações.

Ainda de acordo com MIYAZAKI e FERNANDEZ (2000), diversas empresas que atuam na Internet não têm respeitado a privacidade do consumidor. Ao navegar pelo site de uma empresa, o usuário pode estar sendo monitorado através de cookies, que é a habilidade de identificar informações de visitas às páginas da Internet. Em grande parte das vezes isto ocorre sem o conhecimento do internauta. As informações obtidas são combinadas com os dados pessoais fornecidos previamente pelo usuário, permitindo uma análise do comportamento de busca de informações do consumidor.

Além disto, algumas empresas virtuais podem fornecer os dados dos seus clientes para outras companhias com as quais têm contratos e também utilizam as informações pessoais dos consumidores para o envio de correspondência eletrônica não solicitada. Das 381 empresas virtuais americanas analisadas por MIYAZAKI e FERNANDEZ (2000), apenas 5\% prometeram não realizar contatos não requisitados, $10 \%$ o fariam somente se fosse pedido, $15,7 \%$ ofereceram uma alternativa de não receber correspondências eletrônicas, $2,9 \%$ afirmaram que os contatos iriam ocorrer, mas não ofereciam nenhuma alternativa, caso o usuário não estivesse interessado. As outras $66,4 \%$ empresas virtuais não continham em suas páginas na Internet qualquer informação sobre contatos indesejados. 
MIYAZAKI e FERNANDEZ (2000) também analisaram o nível de comprometimento da empresa junto ao consumidor quanto ao sigilo dos dados pessoais dos usuários para outras empresas interessadas. Cerca de 269 empresas $(70,6 \%)$ não continham algum tipo de informação, nem garantias, sobre o compartilhamento de informações pessoais. Apenas cerca de $17 \%$ garantiam a privacidade do usuário, esclarecendo que as informações fornecidas seriam mantidas em sigilo, evitando assim contatos indesejados por terceiros. Somente $0,5 \%$ destas páginas davam a opção ao internauta de escolher que os seus dados fossem compartilhados, ou não, com outras empresas; $5 \%$ informavam que os dados seriam compartilhados, no entanto fornecendo a alternativa ao usuário de não permitir o envio dos dados e 1,8\% avisavam que os dados seriam compartilhados, sem opções de escolha.

Além da privacidade e segurança, outros tipos de riscos percebidos foram encontrados na literatura para as compras realizadas pela Internet, como: o risco social, de performance, satisfação e tempo (WEBER e ROEHL, 1999; HOFFMAN, 1996).

Devido às características peculiares deste meio de transação, o desenvolvimento do comércio eletrônico tem sido freqüentemente percebido como o precursor do recolhimento do "eu". A compra é realizada sem contatos interpessoais diretos, sendo intermediada pelo computador, podendo levar à deterioração do senso de comunidade, havendo a possibilidade da percepção do risco social. Segundo WEBER e ROEHL (1999), muitos consumidores podem preferir adquirir produtos fora da Internet como uma forma de diversão e oportunidade de interação social.

Pode existir também o risco percebido de performance, ou funcional, considerando que por este meio de negociação não é possível experimentar, tocar ou sentir o que se está adquirindo. A falta de acesso à qualidade do produto foi uma razão de não compra citada por $76 \%$ da amostra de WEBER e ROEHL (1999). Por consequiência, o consumidor pode perceber risco em comprar algo que não satis faça às suas expectativas, desenvolvendo o risco percebido de satisfação.

O tempo também é um fator chave nas compras pela rede, principalmente, para os que não dominam as ferramentas de navegação, tornando o processo lento. O longo tempo de downloads, falhas no design dos sites e falta de links também são alguns dos fatores que influenciam no tempo gasto na procura e escolha dos produtos e serviços pela Internet (HOFFMAN, 1996), podendo levar ao risco percebido do tempo. Além disto, devido ao fato do produto não ser entregue no exato momento da compra, sendo necessário um período para a entrega, geralmente via correio, o consumidor pode sentir receio de não receber a encomenda no tempo esperado.

\section{OBJETIVOS DO ESTUDO}

O objetivo geral dessa investigação foi investigar dimensões de risco percebido em meios de compra, considerando a Internet um canal de marketing, junto de grupos de consumidores que já compraram e dos que nunca compraram através deste meio.

\section{Objetivos específicos}

1. Identificar quais as dimensões de riscos são percebidas por consumidores que nunca compraram pela Internet; 
2. Identificar quais as dimensões de riscos são percebidas por consumidores que já compraram pela rede;

3. Verificar se há diferenças relativas às dimensões de riscos percebidos entre os grupos de consumidores que já compraram e dos que nunca compraram pela Internet.

\section{METODOLOGIA}

O estudo teve caráter exploratório. A pesquisa foi conduzida em duas fases. Na primeira fase, a qualitativa, houve o levantamento de dados secundários e foram realizadas entrevistas pessoais. $\mathrm{Na}$ segunda fase, quantitativa, foi aplicado um questionário, elaborado a partir das informações da primeira fase.

O primeiro passo desse trabalho foi um levantamento teórico do material disponível na área do comportamento do consumidor, tendo como foco o risco percebido. A literatura investigada para a revisão teórica compreendeu um período de quarenta anos, considerando que o risco percebido foi introduzido formalmente na literatura do marketing por BAUER, em 1960.

A esta revisão seguiu-se uma pesquisa qualitativa, que buscou subsídios complementares à literatura para o entendimento do objeto de estudo e construção do questionário para o survey pela Internet. Foram realizadas trinta entrevistas pessoais, sendo a metade da amostra composta por pessoas que já efetuaram pelo menos uma compra pela rede e a outra metade sem ter nunca comprado por este meio, para uma melhor adequação à identificação dos riscos percebidos. As entrevistas foram gravadas com o prévio consentimento dos entrevistados. Posteriormente foram transcritas para a análise de conteúdo, tendo como unidade de mensuração as palavras e frases, buscando identificar tipos de riscos percebidos pela amostra. Visando minimizar a subjetividade da análise foi utilizada uma validação de face do questionário, na qual um segundo pesquisador examinou o conteúdo das entrevistas, por meio de uma sistematização da análise, com o objetivo de verificar se os mesmos tipos de riscos foram identificados (KASSARJIAN, 1977).

\section{Instrumento de coleta de dados}

Com base nas informações obtidas na primeira etapa da pesquisa foi elaborado um questionário. $\mathrm{O}$ bloco das perguntas sobre os riscos percebidos foi composto por 25 itens sobre os principais riscos percebidos encontrados na literatura e identificadas nas entrevistas pessoais, conforme pode ser observado no quadro 1 . Os itens foram agrupados em oito grandes riscos no quadro 1 para facilidade de apresentação pois no questionário os 25 itens foram colocados de forma aleatória. Foram elaboradas frases em que os respondentes indicavam o quanto concordavam ou discordavam da existência destes riscos de comprar pela Internet, finalizando com o risco geral, última questão deste bloco. Foi utilizada uma escala de cinco pontos, do tipo Likert, permitindo aos respondentes atribuir pontos às diferentes categorias de resposta, através de uma escala artificial de pontos que variam de 1 a 5, em que: 1 é concordo totalmente, 2 concordo parcialmente, 3 nem concordo/nem discordo, 4 discordo parcialmente e 5 corresponde a discordo totalmente (ROESCH, 1999; AAKER, 1990; PARASURAMAN, 1986). 
Quadro 1: Riscos percebidos pela compra na Internet.

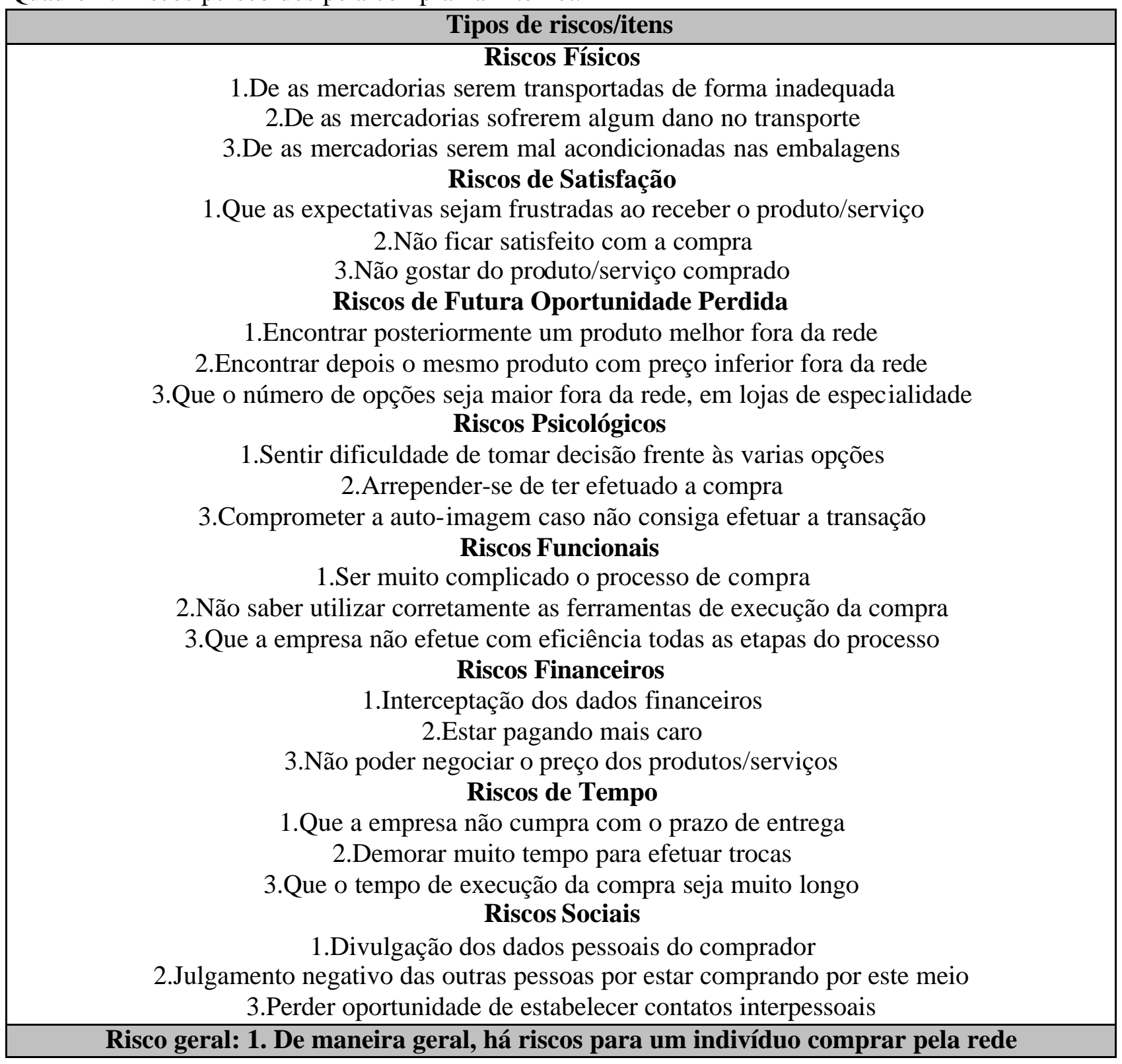

Após a fase de pré-teste, feitos os ajustes necessários, o questionário foi colocado no site da Infoexpert, através de um link, durante dois meses, tempo estimado para serem preenchidas as 200 entrevistas previstas. Ao término, o questionário foi retirado da página da Internet. Visto que todos os questionários recebidos automaticamente continham o e-mail do respondente, foi possível investigar a possibilidade de um indivíduo ter respondido em duplicidade. Quando dois questionários partiam de um mesmo endereço eletrônico, todos os dados contidos nesses foram comparados. Ademais, 20 questionários foram selecionados, aleatoriamente, para a averiguação da veracidade das informações, através de contatos por telefone e e-mail. 


\begin{abstract}
Amostra
A amostra que constituiu esta pesquisa foi de natureza não probabilística, por conveniência e teve como critérios de inclusão: ter nacionalidade brasileira, utilizar a rede por mais de seis meses (visando assim obter uma amostra com um domínio suficiente sobre as ferramentas de navegação) e ter idade superior a 18 anos (teoricamente tendo maior poder de compra e acesso a cartões de crédito).
\end{abstract}

\title{
Técnicas estatísticas para análise dos dados
}

Os dados foram condensados em um banco de dados, de modo a cumprir os objetivos propostos. As técnicas estatísticas empregadas nas análises dos dados da etapa quantitativa foram: estatísticas descritivas, análises de confiabilidade, o teste de Mann-Whitney e a análise fatorial exploratória. $\mathrm{O}$ nível de significância utilizado nas decisões dos testes estatísticos foi de 5,0\% e o nível de confiança nos intervalos, $95,0 \%$.

Para as análises descritivas utilizaram-se a distribuição de freqüência das variáveis, a média e a moda com o objetivo de um conhecimento preliminar do banco de dados e, ao mesmo tempo, para verificar possíveis erros de digitação na entrada do banco de dados (HAIR et al., 1995; CHURCHILL, 1995).

Nesta pesquisa foi utilizado o alfa de Cronbach (CRONBACH, 1951) para verificar a consistência interna dos grupos de itens dos riscos percebidos. Foram considerados como satisfatórios os índices de confiabilidade acima de 0,5 (MALHOTRA, 1993).

Para a questão sobre a diferença do risco percebido foi utilizado o teste de Mann-Whitney (CONOVER, 1980), escolhido pela natureza da escala, que possibilitou examinar as associações entre os grupos dos que nunca compraram pela Internet e dos que já adquiriram produtos ou serviços por este meio. O programa utilizado foi o SAS (Statistical Analysis System), versão 2.12.

A análise fatorial pode ser utilizada para verificar as dimensões relacionadas a um determinado construto (CHURCHILL, 1995), tendo sido realizada neste estudo com o intuito de verificar a existência de diferentes dimensões de riscos percebidos entre os consumidores que compraram e que não efetuaram compras. O programa utilizado foi o SPSS, a rotação foi a varimax e o eingenvalue aceitável de 1 na formação desses fatores. Para a inclusão de itens em um fator, considerourse a carga fatorial mínima de 0,5, sem duplicidade (HAIR et al.,1998).

\section{ANÁLISE E DISCUSSÃO DOS RESULTADOS}

A amostra foi composta por respondentes que nunca haviam comprado pela rede $(55,5 \%)$ e por indivíduos que já adquiriram produtos e serviços por este meio (44,5\%). A maior parte da amostra era solteira $(58,5 \%)$, seguida por casados, com $29 \%$ e $54 \%$ dos respondentes eram do sexo masculino. A idade da amostra variou de 18 até 71 anos. A faixa etária entre 21 e 30 anos compreendeu 55,5\% dos respondentes. A maior parte da amostra havia concluído curso superior $(67,5 \%)$ e $53 \%$ da amostra tinha renda familiar superio r a 20 salários mínimos e 14\% superior a 50 salários mínimos. 


\section{Análise dos riscos percebidos}

Com o intuito de verificar diferenças na percepção do risco quanto à compra pela Internet entre os dois grupos, inicialmente, buscourse aplicar um teste comparativo. A tabela 1 mostra o resultado deste, incluindo a diferença das médias entre os dois grupos. Observa-se que, para os 12 itens marcados com asterisco, ocorreram diferenças significativas entre os que já efetuaram compras pela rede e os que nunca compraram por esse meio $(\mathrm{P}<0,05)$. Para tais itens, o grupo dos que nunca compraram pela Internet percebeu mais risco do que o grupo dos que já compraram pela rede.

Tabela 1: Resultados dos testes comparativos sobre os riscos percebidos quanto à compra pela Internet entre os respondentes que já compraram e os que nunca compraram por este meio.

\begin{tabular}{|c|c|c|}
\hline Tipos de riscos/itens & $\begin{array}{l}\text { Diferença das } \\
\text { médias }\end{array}$ & Valor de $\mathbf{P}$ \\
\hline \multicolumn{3}{|l|}{ Riscos Físicos } \\
\hline 1.De as mercadorias serem transportadas de forma inadequada & 0,27 & 0,1465 \\
\hline 2.De as mercadorias sofrerem algum dano no transporte & $-0,04$ & 0,8934 \\
\hline 3.De as mercadorias serem mal acondicionadas nas embalagens & 0,21 & 0,2750 \\
\hline Riscos de Satisfação & & \\
\hline 1.Que as expectativas sejam frustradas & $0,82 *$ & $<0,001 *$ \\
\hline 2.Não ficar satisfeito com a compra & $0,46 *$ & $0,0026^{*}$ \\
\hline 3.Não gostar do produto/serviço comprado & $0,65 *$ & $<0,001 *$ \\
\hline \multicolumn{3}{|l|}{ Riscos de Futura Oportunidade Perdida } \\
\hline 1.Encontrar posteriormente um produto melhor fora da rede & $0,34 *$ & $0,0243 *$ \\
\hline 2.Encontrar depois o mesmo produto com preço inferior fora da rede & 0,23 & 0,1286 \\
\hline $\begin{array}{l}\text { 3.Que o número de opções seja maior fora da rede } \\
\text { Riscos Psicológicos }\end{array}$ & $0,80 *$ & $<0,001 *$ \\
\hline 1.Sentir dificuldade de tomar decisão frente às varias opções & $-0,27$ & 0,0907 \\
\hline 2.Arrepender-se de ter efetuado a compra & $0,36 *$ & $0,0392 *$ \\
\hline 3.Comprometer a auto-imagem caso não consiga efetuar a transação & 0,18 & 0,3496 \\
\hline $\begin{array}{l}\text { Riscos Funcionais } \\
\text { 1.Ser muito complicado o processo de compra }\end{array}$ & 0,04 & 0,5271 \\
\hline 2.Não saber utilizar corretamente as ferramentas de execução & $-0,18$ & 0,4211 \\
\hline 3.Que a empresa não efetue com eficiência todas as etapas & $0,45 *$ & $0,0024 *$ \\
\hline \multicolumn{3}{|l|}{ Riscos Financeiros } \\
\hline 1.Interceptação dos dados financeiros & $0,54 *$ & $0,001 *$ \\
\hline 2.Estar pagando mais caro & $0,69 *$ & $<0,001 *$ \\
\hline $\begin{array}{l}\text { 3.Não poder negociar o preço dos produtos/serviços } \\
\text { Riscos de Tempo }\end{array}$ & $-0,10$ & 0,7857 \\
\hline 1.Que a empresa não cumpra com o prazo de entrega & 0,08 & 0,6982 \\
\hline 2.Demorar muito tempo para efetuar trocas & 0,25 & 0,0568 \\
\hline 3.Que o tempo de execução da compra seja muito longo & $0,39 *$ & $0,0439 *$ \\
\hline \multicolumn{3}{|l|}{ Riscos Sociais } \\
\hline 1.Divulgação dos dados pessoais do comprador & $0,35 *$ & $0,0188 *$ \\
\hline 2.Julgamento negativo das outras pessoas & 0,05 & 0,6873 \\
\hline 3.Perder oportunidade de estabelecer contatos interpessoais & $-0,06$ & 0,7133 \\
\hline De maneira geral, há riscos para um indivíduo comprar pela rede & $1,02 *$ & $<0,001 *$ \\
\hline
\end{tabular}

Fonte: Teste de Mann-Whitney aplicado ao banco de dados através do programa SAS. Amostra: grupo dos que nunca compraram, n=111; grupo dos que já compraram, $n=89$ e total, $\mathrm{N}=200$. *Ocorreu associação significativa. 
Os autores identificam a existência de diferença de percepção de risco da compra pela Internet entre os grupos, conforme pode ser observado na tabela 1. Dessa forma, supõe-se que os que nunca compraram pela Internet perceberiam mais tipos de risco e com uma maior intensidade dos que os que já compraram, tendo o risco percebido uma relação inversa com a compra por este meio. Os indivíduos que percebem menos risco teriam uma maior tendência a comprar pela Internet. Por sua vez, os que percebem um alto grau de risco em adquirir produtos/serviços pela rede tenderiam a evitar este tipo de compra.

\section{Análise do índice de confiabilidade da escala de risco percebido}

Utilizourse o alfa de Cronbach (CRONBACH, 1951) para verificar a confiabilidade da escala e para cada tipo de risco. Os índices considerados adequados foram os acima de 0,5, seguindo as recomendações de MALHOTRA (1993).

Conforme pode ser observado na tabela 2, a confiabilidade da escala para o grupo dos que nunca compraram pela Internet foi 0,875, para o grupo dos que já compraram, 0,892 e para os dois grupos em conjunto obteve-se um alfa de 0,887 , considerado satisfatório para o estudo.

Tabela 2: Índice de confiabilidade.

\begin{tabular}{l|l|l|l}
\hline & \multicolumn{1}{|c|}{$\begin{array}{c}\text { Nunca comprou } \\
(\mathbf{n = 1 1 1})\end{array}$} & $\begin{array}{c}\text { Já comprou } \\
(\mathbf{n = 8 9})\end{array}$ & \multicolumn{1}{|c|}{ Total (N=200) } \\
\hline Tipos de Riscos & Alfa & Alfa & Alfa \\
\hline 1- Físico & 0,825 & 0,840 & 0,830 \\
2- Satisfação & 0,764 & 0,807 & 0,801 \\
3-Futura oportunidade & 0,829 & 0,747 & 0,798 \\
4- Psicológico & 0,585 & 0,594 & 0,581 \\
5- Funcional & $0,446^{*}$ & 0,533 & $0,481^{*}$ \\
6- Financeiro & $0,422^{*}$ & $0,411^{*}$ & $0,427^{*}$ \\
7- Tempo & $0,487^{*}$ & $0,265^{*}$ & $0,401^{*}$ \\
8- Social & $0,331^{*}$ & $0,279^{*}$ & $0,304^{*}$ \\
\hline Escala (todos os itens) & $\mathbf{0 , 8 7 5}$ & $\mathbf{0 , 8 9 2}$ & $\mathbf{0 , 8 8 7}$ \\
\hline
\end{tabular}

Fonte: Análise de confiabilidade aplicada ao banco de dados através do programa SPSS. *Os valores dos alfas marcados com um asterisco significam que não foram considerados satisfatórios para o estudo.

Para o calculo dos alfas de cada um dos oito tipos de riscos foram incluídos 24 itens, excluindo apenas o "risco geral". Como resultado, conforme demonstra a tabela 2, os riscos considerados com índices satisfatórios foram: o físico, satisfação, futura oportunidade perdida e o psicológico. O risco funcional foi considerado satisfatório apenas para o grupo dos que já compraram pela Internet. 


\section{Análise fatorial dos riscos percebidos}

Com o objetivo de verificar a existência de diferentes dimensões de riscos percebidos na amostra pesquisada, utilizourse a análise fatorial, junto aos 24 itens levantados (com exceção do item risco geral). Considerando que vários itens dos riscos percebidos tiveram associação significativa entre o grupo dos que nunca compraram pela Internet e dos que já adquiriam produtos/serviços por este meio, foram realizadas análises fatoriais separadas para os dois grupos.

\section{Análise fatorial para o grupo dos que nunca compraram pela Internet}

Nesta etapa considerourse o grupo composto por 111 respondentes. Os itens que constam nesta análise são o resultado de um processo de várias rodadas de análise fatorial. Os autores iniciaram a análise fatorial com os 24 itens. Os resultados iniciais apontaram a existência de sete fatores. Em seguida, os itens que estavam em duplicidade ou com cargas inferiores a 0,5 foram excluídos. Posteriormente, foi feita a análise do valor do alfa para cada fator. Foram retirados os itens cuja exclusão possibilitou o aumento do índice de confiabilidade. Como resultado final foram obtidos seis fatores, conforme a tabela 3, englobando 14 itens, com variância explicada de 78,2\% e índice de confiabilidade de 0,79.

Tabela 3: Análise fatorial do risco percebido para o grupo dos que nunca compraram pela Internet.

\begin{tabular}{|c|c|c|c|c|c|c|}
\hline & \multicolumn{6}{|c|}{ Fatores } \\
\hline Itens & 1 & 2 & 3 & 4 & 5 & 6 \\
\hline Fator 1: Risco de satisfação & & & & & & \\
\hline Não gostar do produto/serviço comprado & 0,82 & & & & & \\
\hline Não ficar satisfeito com a compra & 0,80 & & & & & \\
\hline Arrepender-se de ter efetuado a compra & 0,73 & & & & & \\
\hline Fator 2: Risco físico & & & & & & \\
\hline Mercadorias serem transportadas de forma inadequada & & 0,85 & & & & \\
\hline De as mercadorias sofrerem algum dano no transporte & & 0,85 & & & & \\
\hline De as mercadorias serem mal acondicionadas & & 0,80 & & & & \\
\hline Fator 3: Risco de futura oportunidade perdida & & & & & & \\
\hline Encontrar posteriormente um produto melhor fora da rede & & & 0,91 & & & \\
\hline Encontrar depois o mesmo produto com preço inferior & & & 0,88 & & & \\
\hline Fator 4: Risco funcional & & & & & & \\
\hline Ser muito complicado o processo da compra & & & & 0,86 & & \\
\hline Não saber utilizar corretamente as ferramentas & & & & 0,80 & & \\
\hline Fator 5: Risco da proteção da informação & & & & & & \\
\hline Interceptação dos dados financeiros & & & & & 0,85 & \\
\hline Divulgação dos dados pessoais do comprador & & & & & 0,85 & \\
\hline Fator 6: Risco da perda da socialização & & & & & & \\
\hline Perder oportunidade de estabelecer contatos interpessoais & & & & & & 0,92 \\
\hline Não poder negociar o preço dos produtos/serviços & & & & & & 0,67 \\
\hline İndice de confiabilidade - alfa & $\mathbf{0 , 7 9}$ & $\mathbf{0 , 8 2}$ & 0,91 & $\mathbf{0 , 6 3}$ & 0,62 & $\mathbf{0 , 6 0}$ \\
\hline
\end{tabular}


Verifica-se que o primeiro fator, denominado de risco de satisfação (ROEHL e FESENMAIER,1992), é composto por três itens. Destes, o que se refere a "arrepender-se de ter efetuado a compra" foi, inicialmente, colocado em uma outra categoria de risco. Entretanto, a análise fatorial agrupou esse item junto aos outros que mens uram o risco de satisfação. Este item foi mantido neste fator, pois a literatura comenta que, caso o consumidor não venha a gostar do produto ou serviço, ou não ficar satisfeito com a compra, provavelmente se arrependerá de tê-la efetuado (ENGEL et al., 1995). É o aspecto da dissonância cognitiva que, por muito tempo, foi a única explicação para a satisfação/insatisfação do consumidor.

$\mathrm{O}$ segundo fator incluiu os itens do risco físico das mercadorias e bens adquiridos pela rede (LOVELOCK e WRIGHT, 1998). Esse fator foi agrupado da mesma forma que originalmente os autores tinham proposto, incluindo os mesmos itens.

No terceiro fator foram agrupados itens do risco de futura oportunidade perdida (VANN, 1984; ZIKMUND e SCOTT, 1974) e, no quarto fator, do risco funcional (SOLOMON,1998).

Verifica-se que o quinto fator, denominado de "risco da proteção da informação", é composto por dois itens: divulgação dos dados pessoais e interceptação dos dados financeiros. Estes foram, inicialmente, alocados como sendo risco social e risco financeiro, nesta ordem. Analisando a teoria, como os estudos de MIYAZAKI e FERNANDEZ (2000) e LASCH (1998), estes dois itens poderiam mensurar o risco percebido do sigilo das informações, da sua transmissão e da privacidade do comprador. Estes autores consideram o receio da divulgação do número do cartão de crédito, renda e outras informações pessoais como o risco percebido de proteção da informação.

O sexto fator, denominado de "risco da perda da socialização", incluiu os seguintes riscos: perder contatos interpessoais e não poder negociar o preço dos produtos/serviços. A princípio, considerou-se estes dois itens como risco social e financeiro, respectivamente. Entretanto, justifica-se a análise destes dois itens agrupados visto que pela Internet perde-se o contato humano das trocas. $\mathrm{O}$ contato intermediado pelo computador faz que haja uma perda de contatos pessoais, dificultando o processo de negociação. FORMAN e SRIRAM apud WEBER e ROEHL (1999) citam esse tipo de risco, destacando que muitos consumidores têm preferência em buscar informações e adquirir produtos e serviços fora da Internet como uma fonte de entretenimento e oportunidade de interação social.

\section{Análise fatorial para o grupo dos que já compraram pela Internet}

Para esta etapa, considerou-se o grupo composto por 89 respondentes. Os resultados iniciais apontaram a existência de sete fatores. Os itens que constam nesta análise são o resultado de um processo de purificação da escala. Como resultado ficaram quatro fatores, englobando 10 itens, com a variância explicada de 79,1\% e índice de confiabilidade para a escala de 0,80. A tabela 4 apresenta os resultados desta análise. 
Tabela 4: Análise fatorial do risco percebido para o grupo dos que já compraram pela Internet

\begin{tabular}{l|l|l|l|l}
\hline & \multicolumn{2}{|c}{ Fatores } \\
\hline Itens & $\mathbf{1}$ & $\mathbf{2}$ & $\mathbf{3}$ & $\mathbf{4}$ \\
\hline Fator 1: Risco de futura oportunidade perdida & & & & \\
Encontrar posteriormente um produto melhor fora da rede & 0,89 & & & \\
Encontrar depois o mesmo produto com preço inferior fora da rede & 0,86 & & & \\
Não ficar satisfeito com a compra & 0,85 & & & \\
Fator 2: Risco físico & & \multirow{2}{*}{0,89} & & \\
De as mercadorias sofrerem dano no transporte & & 0,85 & & \\
De as mercadorias serem transportadas de forma inadequada & & 0,77 & & \\
De as mercadorias serem mal acondicionadas & & & & \\
Fator 3: Risco da proteção da informação & & & 0,90 & \\
Divulgação dos dados pessoais do comprador & & & 0,88 & \\
Interceptação dos dados financeiros & & & & 0,85 \\
Fator 4: Risco psicossocial & & & & 0,84 \\
Comprometer a auto-imagem caso não consiga efetuar a transação & & & \\
Julgamento negativo por estar comprando por este meio & & & \\
\hline Indice de confiabilidade - alfa & & & \\
\hline
\end{tabular}

Fonte: Análises multivariadas aplicadas ao banco de dados através do programa SPSS. Método de extração: Principal Component Analysis. Método de rotação: Varimax with Kaiser Normalization. Amostra: grupo 2, n=89.

O primeiro fator, denominado de risco de futura oportunidade perdida (VANN, 1984; ZIKMUND e SCOTT, 1974), é composto por três itens, sendo que, o que se refere a "não ficar satisfeito com a compra" foi, a princípio, imaginado como fazendo parte do risco de satisfação. Após a compra de algum produto ou serviço pela Internet, é possível encontrar um produto melhor, ou o mesmo com um preço inferior, situação que poderia levar o consumidor à insatisfação em relação à compra atual, causando a dissonância cognitiva (ENGEL et al., 1995). O segundo fator englobou os itens do risco físico das mercadorias adquiridas pela rede (LOVELOCK e WRIGHT, 1998). Este fator foi agrupado da mesma forma que originalmente os autores tinham proposto, mantendo os mesmos itens.

No terceiro fator foram incluídos os itens do "risco de proteção da informação" transmitida pela Internet, como foi apresentado, anteriormente, na análise fatorial do grupo dos que nunca compraram pela rede.

O quarto fator, denominado de "risco psicossocial", agr upou itens do risco social (julgamento negativo das outras pessoas por estar comprando por este meio) e do risco psicológico (comprometer a autoimagem caso não consiga efetuar a transação). Alguns autores estudaram os riscos psicológicos e sociais como sendo um único tipo, os psicossociais (STEM et al., 1977; TAYLOR, 1974; CUNNINGHAM,1967).

\section{CONSIDERAÇÕES FINAIS}

Os usuários da Internet que compram pela rede percebem menos riscos do que os que nunca compraram por esse meio. Apesar do senso comum apontar para esse fato, há pouca evidência empírica 
para tal. Ademais, pouco se sabe sobre as tipologias de riscos percebidos quanto à compra por esse meio e a diferença entre as percepções de diferentes tipos de riscos entre usuários da rede. Nesse sentido, os resultados desse estudo apontam tipologias mais variadas de dimensões de risco percebidos presentes para o grupo dos que nunca compraram pela Internet, com seis dimensões do risco percebido, enquanto que, para os que já compraram por esse meio, verificaram-se quatro. Os usuários que nunca compraram pela rede também perceberam um maior grau de risco para todos os itens analisados.

$\mathrm{Na}$ análise fatorial do grupo dos que nunca compraram pela Internet as dimensões de satisfação e perda da socialização foram incluídas, com um alto nível de risco percebido pelos respondentes, sendo riscos mais específicos para as pessoas que nunca compraram do que para os indivíduos que já adquiriram produtos/serviços pela rede. Por sua vez, os riscos físicos, de futura oportunidade perdida e da proteção da transmissão da informação na compra pela Internet surgiram na análise fatorial de ambos os grupos. Essas dimensões de risco são percebidas tanto pelos que nunca compraram pela rede quanto pelos que já efetuaram compras por este meio. As outras dimensões, como a funcional, para o grupo dos que nunca compraram pela rede e a psicossocial, para os que já adquiriram produtos/serviços por este meio não indicam um alto grau risco percebido pela amostra quanto as dimensões comentadas anteriormente.

Conclui-se que, na elaboração de redutores de riscos para usuários da Internet, é necessário lidar de formas diferentes com estes dois grupos devido ao fato do grupo dos que nunca compraram perceberem mais tipos de riscos e em um maior grau do que o grupo dos que já adquiriram produtos ou serviços por este meio. A satisfação e a perda da socialização são aspectos importantes a serem trabalhados para o incentivo dos indivíduos que nunca compraram pela rede. Por sua vez, os riscos físicos e, principalmente, os de futura oportunidade perdida e da proteção da informação devem ser analisados para a criação de estratégias de redução de risco tanto para os que compram, bem como para os que ainda não compraram por este meio. Os resultados indicam que os riscos influenciam a decisão de adquirir produtos e serviços pela rede, havendo uma relação inversa entre risco percebido e a predisposição para a compra por esse meio.

\section{IMPLICAÇÕES GERENCIAIS}

As empresas que atuam ou que pretendem atuar no comércio eletrônico devem implementar formas de redução dos riscos percebido por seus clientes em potencial, considerando a influência desse na decisão de compra on-line.

Salienta-se que o risco possui diferentes dimensões e níveis de percepção entre os indivíduos que já efetuaram compras por este meio e os que nunca compraram. Portanto, é necessário que as empresas apliquem estratégias específicas para cada grupo, identificando os tipos de risco comuns e os particulares a cada grupo.

Certos tipos de risco parecem ser ma is característicos de usuários que nunca compraram pela rede, tais como: "satisfação" e "perda de socialização". As empresas, na busca de implementar seus negócios, precisam desenvolver um trabalho direcionado que vise minimizar esses riscos, tendo como público alvo essa população. O desenvolvimento de garantias como a devolução do pagamento efetuado, caso o consumidor não fique satisfeito, pode ser uma opção de redução de risco de satisfação. Quanto à perda de socialização, há a possibilidade da apresentação de sites com apelos visuais e auditivos que supram 
a carência de contato humano. Ademais, a interatividade pode ser a maior ferramenta para atenuar a percepção desse risco.

A percepção de riscos físicos dos bens adquiridos pela Internet, identificada pelos usuários que compram por este meio e pelos que nunca compraram, exige uma estratégia de redução de risco que ofereça ressarcimento, caso a mercadoria chegue com danos. A possibilidade de acompanhamento do pedido, disponibilizado on-line, com descrições detalhadas, que possam ser acessadas a qualquer hora pelo consumidor, pode fortalecer a confiança do mesmo.

$\mathrm{O}$ risco de futura oportunidade perdida, de encontrar posteriormente o mesmo bem com um preço inferior fora da rede ou um produto melhor após a compra, parece ser uma preocupação dos usuários que já compraram por este meio e dos que nunca compraram. Recomenda-se a oferta de preços competitivos e mercadorias com tecnologia atualizada.

A segurança parece ser um fator chave. Surge, assim, a necessidade da adoção de medidas que garantam, cada vez mais, a proteção de todos os procedimentos de um pedido eletrônico, desde a transmissão até o armazenamento dos dados. Quanto ao receio de enviar o número do cartão de crédito pela Internet, poderiam ser oferecidas formas alternativas, incluindo o fornecimento desse (ou parte) via fax, telefone ou e-mail. Algumas medidas podem atenuar a percepção deste risco, tais como: informar aos usuários quais os procedimentos de segurança utilizados e as garantias caso alguma fraude ocorra, por exemplo, o reembolso de débitos não autorizados no cartão de crédito que resultem de falha do sistema de segurança da empresa. Ademais, a utilização da figura do fiel depositário, que intermediaria o pagamento entre consumidor e empresa, poderia diminuir a preocupação quanto à interceptação dos dados financeiros pela rede e o receio de efetuar o pagamento e não receber a mercadoria.

A dificuldade de negociação do preço por este meio de compra poderia ser contornada através da adoção de leilão reverso. O usuário informaria quanto estaria disposto a pagar por determinado produto ou serviço e as empresas interessadas entrariam em contato com tal consumidor para proceder a negociação.

O uso indevido dos bancos de dados também deve receber atenção das empresas que desejem implantar operações neste meio. A comercialização desses tem permitido que os usuários recebam correspondências não solicitadas, ameaçando a sua privacidade. Recomenda-se que esteja disponível, dentro do próprio formulário de cadastramento de clientes da empresa virtual, a opção de proibição do uso de seus dados pessoais por terceiros. Deve-se, também, assegurar aos consumidores que não optem em restringir o uso de seus dados a possibilidade de retirada de seus nomes quando desejarem.

Os autores supõem que as empresas que considerem os riscos percebidos dos clientes em potencial e que busquem a adoção de estratégias que minimizem esses riscos podem obter uma vantagem competitiva frente aos seus concorrentes.

\section{SUGESTÕES PARA FUTURAS PESQUISAS}

Considerando a escassez da literatura nacional na área de risco percebido em meios de compra, há um vasto campo de trabalho a ser desenvolvido nesta área. Algumas sugestões para futuras pesquisas são apresentadas a seguir: 
- Estudar a percepção de consumidores em diferentes países sobre o risco da compra on-line (estudos do tipo cross-cultural). De acordo com SCHIFFMAN e KANUK (1997), nem todas as pessoas no mundo demonstram o mesmo nível de percepção de risco. Assim, empresas que têm negócios em diversos países não podem generalizar os resultados dos estudos sobre risco percebido realizados em um país para outros países sem uma pesquisa adicional.

- A comparação dos riscos percebidos na compra através de diversos meios como, por exemplo, Internet versus catálogo ou telefone.

- Visando aprimorar a análise sobre a influência dos riscos percebidos em meios de compra, sugerese incluir e controlar outras variáveis como, por exemplo, características individuais dos consumidores.

\section{REFERÊNCIAS BIBLIOGRÁFICAS}

AAKER, David A. Marketing research. 4. ed. Belmont: John Wiley \& Sons, 1990.

BAUER, Raymond. Consumer behavior as risk-taking. Proceedings of the $43^{\text {rd }}$ Conference of The American Marketing Association, p.389-398, 1960.

CHURCHILL, Gilbert. Marketing research: methodological foundations. 6 ed. Orlando: The Dryden Press, 1995.

CRONBACH, Lee. Coefficient alpha and the internal structure of tests. Psychometrical,v.16, n.3, p.297-334, Sept. 1951.

CUNNINGHAM, S. M. The major dimensions of perceived risk. Boston: Harvard University Press, $\mathrm{p}$. 82-108, 1967.

ENGEL, James F.; BLACKWELL, Roger D. e MINIARD, Paul W. Consumer Behavior. 8. ed. Orlando: The Dryden Press, 1995. 951 p. Bibliografia: p. 441- 442. ISBN: 0030984645.

GIGLIO, Ernesto. O comportamento do consumidor e a gerência de marketing. São Paulo: Pioneira, 1996.

GONÇALVES, Cid Filho; SOARES, Fábio Croso; ALBERTO, Carlos et al. Comércio Eletrônico na Internet: Uma Pesquisa Exploratória no Mercado Consumidor. Encontro Nacional da ANPAD, 1998. Anais... CD- ROM.

HAIR, Joseph F. Jr.; ANDERSON, Ralph E.; TATHAM, Ronald L. et al. Multivariate data analysis with readings. 4 ed. Englewood Cliffs: Prentice Hall, 1995.

. Multivariate data analysis. 5 ed. Upper Saddler River: Prentice Hall, 1998.

HOFFMAN, Donna L. Marketing in hypermedia computer-mediated environments: conceptual foundations. Journal of Marketing, p.50-58, july 1996. 
KASSARJIAN, Harold H. Content analysis in consumer research. Journal of Consumer Research, v. 4, p. 8-18, june 1977.

KIANI, G. Marketing opportunities in the digital world. Internet Research, v. 8, p. 185-194, 1998.

LASCH, Erin. Do you trust the web? Ohio CPA Journal, Columbus, v.57, n.4, p.8-11, oct./dec. 1998. ISSN: 07498284

LOVELOCK, Christopher e WRIGHT, Lauren Principles of service marketing and management. New Jersey: Prentice Hall, 1998. ISBN: 013676875

MALHOTRA, Naresh K. Marketing research: an applied orientation. New Jersey: Prentice Hall, 1993. 857 p. ISBN: 0135553504

MIYAZAKI, Anthony D. e FERNANDEZ, Ana. Internet privacy and security: an examination of online retailer disclosures. Journal of Public Policy \& Marketing, Ann Arbor, v. 19, n.1, p.54, spring 2000. ISSN: 07439156

NUNOMURA, Eduardo. O Perigo na rede. Entrevista: Mark Abene. Veja, São Paulo, n.1562, p.11-15, 2 set.1998.

PARASURAMAN, A. Marketing research. Canada: Addison-Wesley Publishing Company, 1986.

ROEHL, Wesley S. e FESENMAIER, Daniel R. Risk perceptions and pleasure travel: an exploratory analysis. Journal of Travel Research, Boulder, v.30, n.4, p.17- 22, spring 1992. ISSN: 00472875

ROESCH, Sylvia Maria Azevedo. Projetos de estágio e de pesquisa em administração. 2.ed. São Paulo: Atlas,1999. ISBN: 8522423385

ROHM, Andrew J. e MILNE, George R. Emerging marketing and policy issues in electronic commerce: attitudes and beliefs of Internet users. Marketing and Public Policy Proceedings, v.8, p. 7379, 1998.

SCHIFFMAN, L. G. e KANUK, Leslie L. Comportamento do consumidor. Tradução: Vicente Abrósio. 6. ed. Rio de Janeiro: LTC, 1997.

SITKIN, Sim B. e PABLO, Amy L. Reconceptualizing the determinants of risk behavior. The Academy of Management Review, Mississippi State, v. 17, n. 1, p. 9-39, jan. 1992. ISSN: 03637425

SOLOMON, Michael R., Consumer behavior: buying, having and being. 4. ed. New Jersey: Prentice Hall, 1998. 640 p. Bibliografia: p. 280-281 ISBN: 0137957254

STEM, D.E. Jr.; LAMB, C.W. Jr. e MACLACHLAN, D.L. Perceived risk: a synthesis. European Journal of Marketing, Bradford, v. 11, n. 4, p. 312, 1977. ISSN:03090566

TAYLOR, James W. The role of risk in cons umer behavior. Journal of Marketing, v.38, p.54-60, apr. 1974.

VANN, John W. A multi-distributional, conceptual framework for the study of perceived risk, Advances in Consumer Research, v. 11, p.442-446, 1984. 
WEBER, E. U. e BOTTOM, W. P. Axioral measures of perceived risk: some tests and extensions. Journal of Behavioral Decision Making, v.2, n.2, p.113-131, 1989.

WEBER, Karin e ROEHL, Wesley S. Profiling people searching for the purchasing travel products on the World Wide Web. Journal of Travel Research, Boulder, v.37, n.3, p.291-298, 1999.ISSN:00472875

ZIKMUND, William G. e SCOTT, Jerome E. Variety analysis of perceived risk self-confidence and information sources. Advances in Consumer Research, v. 1, p. 406- 416, 1974.

\section{AGRADECIMENTOS}

à Universidade Federal de Pernambuco UFPE / PROPAD e à Faculdade Integrada do Recife - FIR / COPESQ pelo apoio e incentivo bem como à CAPES pelo suporte financeiro.

\section{Artigo recebido em 13.01.2003. Aprovado em 19.02.2004.}

\section{Michelle H. Kovacs}

Professora e pesquisadora da Faculdade Integrada do Recife (FIR) e Doutoranda em Administração pela Universidade Federal de Pernambuco - PROPAD.

Interesses de pesquisa: comportamento do consumidor, riscos percebidos, comércio eletrônico.

E-mail: kovacs@fir.br

Endereço: Rua Setúbal 860/B apt.1103 Boa Viagem Recife - PE, 51030-010.

\section{Salomão A. de Farias}

Professor e pesquisador da Universidade Federal de Pernambuco -PROPAD. Doutor em Administração pela USP.

Interesses de pesquisa: comportamento do consumidor, marketing de serviços, satisfação do cliente, varejo na Internet e marketing para terceira idade.

E-mail: saf@ufpe.br

Endereço: Rua Rodrigues de Mendonça, 45 Apto. 1103 Prado Recife -PE, 50720-170. 